\title{
A comparison of the effects of ethanol and chlordiazepoxide on exploration and on its habituation
}

\author{
SANDRA E. FILE \\ Pharmacology Department, The School of Pharmacy, University of London, England
}

\begin{abstract}
Low doses of ethanol $(0.4 \mathrm{~g} / \mathrm{kg})$ and chlordiazepoxide $(5 \mathrm{mg} / \mathrm{kg})$ increased exploration by rats on Trial 1 in a simple test situation, but the increase failed to reach significance when the situation was more complex. Ethanol $(0.4 \mathrm{~g} / \mathrm{kg})$ impaired the response to a stimulus change since all groups except this showed increased head-dipping from Trial 1 to Trial 2 if objects were introduced on the second trial. Neither dose of ethanol impaired between-trial habituation of exploration, but chlordiazepoxide $(5 \mathrm{mg} / \mathrm{kg})$ retarded habituation and chlordiazepoxide $(7.5 \mathrm{mg} / \mathrm{kg})$ prevented it. While increased exploration might be ascribed to antianxiety actions of these drugs, impairments, specific to each drug, are also produced.
\end{abstract}

When an animal is placed in a novel situation, both fear and exploration are evoked (Archer, 1973; King \& Appelbaum, 1973), and generally these two factors seem to be inversely related (Aitken, 1974; Halliday, 1968; Russell, 1973), although it has been suggested that they are independent dimensions (Denenberg, 1969) or even are positively related (Halliday, 1967). If there is an inverse relationship between the level of exploration in a novel situation and the amount of fear elicited by that situation, then anxiolytics should increase exploration.

It is the purpose of this experiment to examine the effects of two anxiety-reducing drugs (ethanol and chlordiazepoxide) on exploration by rats placed in a four-hole holeboard. The reliability of headdipping in a holeboard has been studied (File \& Wardill, 1975a), and its validity as a measure of exploration rather than of motor activity has been established (File \& Wardill, 1975b). Motor activity is involved only minimally in head-dipping-the animal has to move to reach the holes, but can do so slowly or with ataxia. This experiment will also examine whether the drug effects on exploration are dependent on the complexity of the test situation, and whether the drugs affect the response of animals to a stimulus change in the test situation. Ethanol $(0.4$ and $0.8 \mathrm{~g} / \mathrm{kg})$ has been found to increase exploration in mice measured by head-dipping (File \& Wardill, 1975a), and so these two doses were chosen for study in rats. Nolan and Parkes (1973)

This work was supported partly by a Roche Research Fellowship to S.E.F. and partly by a Science Research Council grant to Dr. M. J. Neal. I am grateful to Miriam Rushton for technical assistance. Send requests for reprints to: Dr. S. File, Department of Pharmacology, The School of Pharmacy, University of London, 29/39 Brunswick Square, London WC1N 1AX, England. found that 5 and $7.5 \mathrm{mg} / \mathrm{kg}$ chlordiazepoxide (CDP) increased head-dipping in mice, but Hughes (1972, Hughes \& Grieg, 1975) found that $5 \mathrm{mg} / \mathrm{kg}$ led to a decrease in the time spent by rats in the novel side of the box. The doses 5 and $7.5 \mathrm{mg} / \mathrm{kg}$ were therefore chosen to study the effects of CDP on head-dipping in rats.

It has already been suggested that CDP increases exploration because of its anxiety-reducing action, and therefore is without effect when the situation is familiar to the animal, and hence less anxiety arousing (Marriott \& Smith, 1972). If this is so, then anxiolytics should have no effect, or a reduced effect, on the second trial in a test situation, provided that the first trial was long enough for the rats to have learned sufficient features for the situation to have become familiar. The second purpose of this experiment was to examine the effects of ethanol and chlordiazepoxide on the between-trial habituation of exploration. Changes in habituation may simply be secondary to any drug-induced changes in the initial level of exploration. Or the drugs may have more than one effect on behavior, and it is possible that as well as, say, increasing exploration on Trial 1, the drug may also impair retention of information about the situation, and so the level of exploration on Trial 2 might not decrease.

\section{METHODS}

\begin{abstract}
Animals
Male hooded rats, $300-350 \mathrm{~g}$, supplied by Olac Ltd., Bicester, were housed six per cage $(30 \times 50.5 \mathrm{~cm})$, in a room temperature of $25^{\circ} \mathrm{C}$ and in an 11-h light/13-h dark cycle, with food and water ad lib. All animals had been in the laboratory for 4 weeks before testing and had been extensively handled.
\end{abstract}

\section{Apparatus}

The holeboard was $50 \times 60 \mathrm{~cm}$, with walls $47 \mathrm{~cm}$ high, and 
four holes in the floor. The objects placed under the holes were a rubber bund, a pot of matches, a glass funnel, and a metal weight. The illuminance on the floor of the box was 25 scotopic lux, measured with a photocell calibrated with respect to the C.I.E. scotopic curve and to the C.I.E. standard radiator.

\section{Drugs}

A $20 \%$ (by volume) solution was made by dissolving spectroscopic absolute ethanol (B.D.H. Chemicals Ltd.) in distilled water. This gave a concentration of $0.16 \mathrm{~g} / \mathrm{ml}$. Chlordiazepoxide hydrochloride (Roche Products Ltd.) was dissolved in distilled water to a concentration of $2 \mathrm{mg} / \mathrm{ml}$.

\section{Procedure}

Rats were randomly assigned to the water, ethanol $(0.4$ and $0.8 \mathrm{~g} / \mathrm{kg}$ ), and chlordiazepoxide (CDP) $(5$ and $7.5 \mathrm{mg} / \mathrm{kg}$ ) groups. Since the testing of ethanol and CDP took place consecutively, a water control group was tested with each drug. The groups were divided into three subgroups with 10 rats in each. One subgroup received two trials in the holeboard without any objects on either trial (A-A); another subgroup was tested without objects on Trial 1, but in the presence of objects on Trial 2 (A-P); the last subgroup was tested with objects present on both trials (P-P).

Testing took place only between 1000 and $1200 \mathrm{~h}$ because of variance in head-dipping with the time of day (File \& Day, 1972). Nine rats were tested each day, and the test order within and between days was randomized between the groups. All rats received two 10-min trials, separated by $24 \mathrm{~h}$, so that for each rat the retest trial was at the same time of day as on Trial 1. On each occasion, injections were given IP 30 min before testing, a time at which both ethanol and CDP would be having their peak effect.

Each rat was placed in the center of the holeboard, facing away from the observer, and the number of head dips and the duration of head-dipping (to the nearest second) were recorded. The number of rears was also counted, including both freestanding rears and those against the sides of the box. At the end of the trial, any boluses were removed and the floor of the holeboard was washed and dried in order to remove any traces of the path taken.

\section{RESULTS}

When an animal is first placed in a novel environment, anxiety due to unfamiliarity with the test situation is at its highest. Effects of the drugs that might be ascribable to anxiety reduction should therefore be reflected in Trial 1 performance. Figure 1 shows the frequency and duration of headdipping for the water and ethanol $(0.4 \& 0.8 \mathrm{~g} / \mathrm{kg})$ groups over two trials in the holeboard, in the absence of objects (A) and in their presence (P). From this figure it can be seen that, in the absence of objects, ethanol $(0.4 \mathrm{~g} / \mathrm{kg})$ did increase both the frequency and the duration of head-dipping on Trial $1(\mathrm{t}=2.12$ and 1.89 , respectively, $\mathrm{df}=38$, $\mathrm{p}<.025$ and $\mathrm{p}<.05$ ).

Similarly, from Figure 2, it can be seen that in the absence of objects on Trial 1, CDP $(5 \mathrm{mg} / \mathrm{kg})$ also increased both the frequency and the duration of head-dipping, the latter being significant $(t=2.03$, $\mathrm{df}=38, \mathrm{p}<.025)$. If the increased head-dipping on Trial 1 is due to an anxiety-reduction effect of the drugs, then these drugs should have been producing their maximum effects during the first part of Trial 1, before any changes due to learning


Figure 1. The frequency and duration of head-dipping over two trials in the holeboard, in the absence (A) and in the presence (P) of objects for rats injected with water and ethanol (0.4 and $0.8 \mathrm{~g} / \mathrm{kg}$ ). Each point is the mean of 10 scores.
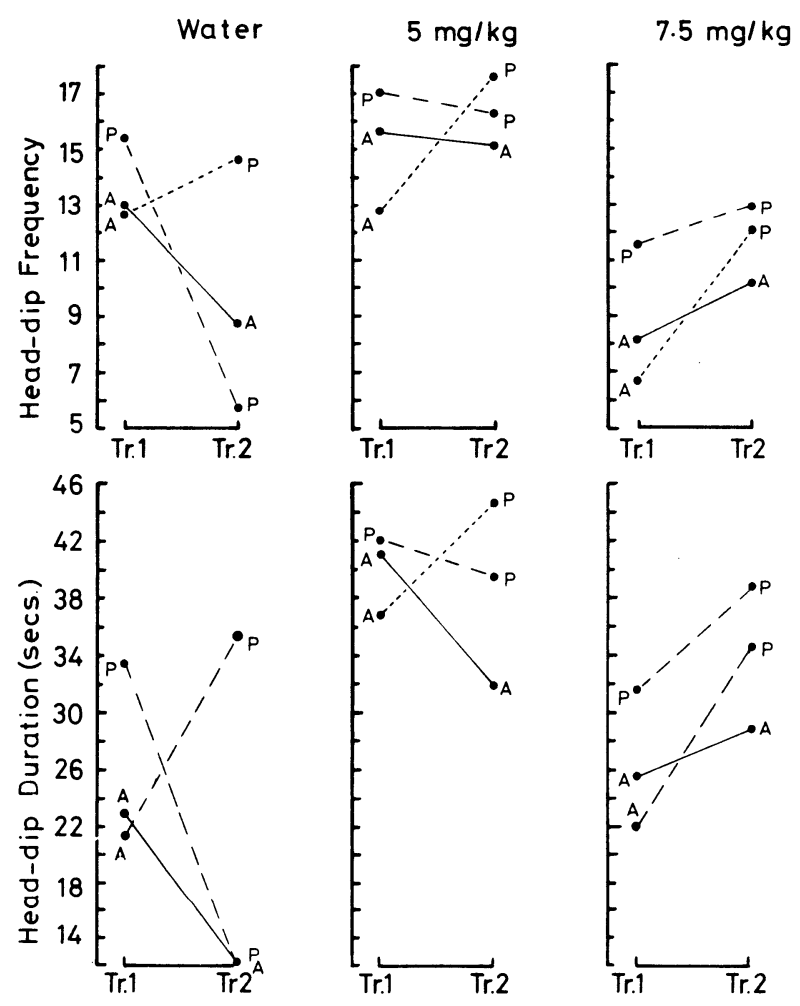

Figure 2. The frequency and duration of head-dipping over two trials in the holeboard, in the absence (A) and in the presence (P) of objects, for rats injected with water and chlordiazepoxide ( 5 and $7.5 \mathrm{mg} / \mathrm{kg}$ ). Each point is the mean of 10 scores. 
had occurred. In order to examine this, the scores for the controls and the low doses of ethanol and CDP were analyzed for changes within Trial 1 , by taking the duration of head-dipping that occurred in each 2.5 min period (see Figure 3). From Figure 3, it can be seen that most of the increased head-dipping produced by ethanol occurred in the first $2.5 \mathrm{~min}$, and by the second half of the test, the difference between the ethanol-injected rats and the controls had disappeared. Although the CDP rats also had a higher head-dip score during the first $2.5 \mathrm{~min}$, their increased duration of head-dipping on Trial 1 was also due to the failure to show a within-session decrease until the last trial period. This suggests that CDP may impair habituation as well as having an effect on exploration through anxiety reduction.

The increased exploration on Trial 1 , possibly due to anxiety reduction effects of ethanol and CDP, did not reach significance when the animals were tested in the presence of objects (see Figures 1 and 2). In all groups, the duration of head-dipping on Trial 1 was higher in the presence of objects than it was in their absence, and this difference was significant for the controls, the ethanol $(0.8 \mathrm{~g} / \mathrm{kg})$ and the CDP $(7.5 \mathrm{mg} / \mathrm{kg})$ groups $(\mathrm{t}=2.12,2.06$, and 2.25 , $\mathrm{df}=28, \mathrm{p}<.025)$, but not for the low doses of ethanol or CDP. At this point, the similarities between the effects of the two drugs end and each must now be considered separately.



Figure 3. Duration of head-dipping over four 2.5-min periods within Trial 1, for water-injected controls ( $---\bullet$ and $0--0)$, ethanol $(0.4 \mathrm{~g} / \mathrm{kg}, \bullet-\bullet)$, and CDP $(5 \mathrm{mg} / \mathrm{kg}$, $\mathrm{O}-\mathrm{O})$. The rats were tested in the absence of objects and each point is the mean of 10 scores.
The rats injected with ethanol $(0.4 \mathrm{~g} / \mathrm{kg})$ had not shown significantly more head-dipping on Trial 1 in the presence of objects than they had done in their absence. This dose of ethanol also reduced responsivity to the introduction of objects on Trial 2 , and in this case there was no increase in head-dipping from Trial 1 (objects absent) to Trial 2 (objects present). In contrast, both the controls and the ethanol $(0.8 \mathrm{~g} / \mathrm{kg})$ groups showed a significant increase in the duration of head-dipping when objects were introduced on Trial $2(t=2.85$ and $2.79, \mathrm{df}=9$, $\mathrm{p}<.01$ and .025).

Neither dose of ethanol impaired the retention of information about the environment, reflected in habituation from Trial 1 to Trial 2 in both the A-A and the P-P conditions and for both the frequency and the duration measures ( $p<.05$ in all cases). Although the pattern of head-dipping shown by the ethanol $(0.8 \mathrm{~g} / \mathrm{kg})$ group was in every respect similar to that shown by the controls, this dose did significantly reduce the number of rears made in the absence of objects, from a control level of 30.5 to a mean of $16.8(\mathrm{t}=4.0, \mathrm{df}=38, \mathrm{p}<.001)$ and in the presence of objects from a control mean of 34.0 to a mean of $16.9(\mathrm{t}=4.3, \mathrm{df}=38, \mathrm{p}<.001)$, which may well have been due to motor impairments produced by this dose. The lower dose of ethanol had no effect on the number of rears made.

CDP differed from ethanol in that it did not impair the responsivity to objects when these were introduced on Trial 2. All groups showed an increase in head-dipping from Trial 1 to Trial 2 (for frequency: $t=1.11, p>.05$, for water; $t=2.82$, $\mathrm{p}<.025$, for $5 \mathrm{mg} / \mathrm{kg} \mathrm{CDP}$; and $\mathrm{t}=4.22, \mathrm{p}<.05$, for $7.5 \mathrm{mg} / \mathrm{kg}$ CDP: $\mathrm{df}=9$ in all cases; and for duration: $\mathrm{t}=2.09, \mathrm{p}<.05 ; \mathrm{t}=1.54, \mathrm{p}>.05$; and $\mathrm{t}=2.32, \mathrm{p}<.025 ;$ respectively, $\mathrm{df}=9$ ).

A second difference from the effects of ethanol was that CDP impaired habituation. In the simpler test condition, the water-injected controls showed habituation of both the frequency and the duration of head-dips $(t=2.35$ and $t=1.93, p<.025$ and $\mathrm{p}<.05$, respectively), while only the duration of head-dipping showed habituation for the CDP $(5 \mathrm{mg} / \mathrm{kg})$ group $(\mathrm{t}=2.37, \mathrm{p}<.025)$. The CDP $(7.5 \mathrm{mg} / \mathrm{kg})$ group actually showed an increase in the frequency and duration of head-dipping from Trial 1 to Trial 2. In the more complex situation, the controls again showed habituation of both measures $(t=3.88, p<.005$, and $t=3.06, p<.01$, $\mathrm{df}=9$ ), neither of the CDP groups showed any habituation, and the $7.5-\mathrm{mg} / \mathrm{kg}$ group again showed an increase over trials. Thus, the impairment of habituation produced by CDP was dose-related and also related to the complexity of the test environment.

CDP reduced the number of rears shown in the absence of objects from the control level of 42.5 to a mean of 7.4 for the $7.5-\mathrm{mg} / \mathrm{kg}$ group $(\mathrm{t}=6.25$, 
$\mathrm{df}=38, \mathrm{p}<.005)$. In the presence of objects, both doses reduced the number of rears from a control level of 34.0 to a mean of 19.8 for the $5-\mathrm{mg} / \mathrm{kg}$ group $(\mathrm{t}=2.75, \mathrm{df}=18, \mathrm{p}<.01)$ and to a mean of 9.7 for the $7.5-\mathrm{mg} / \mathrm{kg}$ group $(\mathrm{t}=4.74, \mathrm{df}=18, \mathrm{p}<.005)$. The reduction in rears may be due to the muscle relaxant properties of CDP.

\section{DISCUSSION}

The increase in exploration on Trial 1 following ethanol $(0.4 \mathrm{~g} / \mathrm{kg})$ and chlordiazepoxide $(5 \mathrm{mg} / \mathrm{kg})$ was significant only when the rats were tested in the absence of objects. The failure to get a significant increase in the presence of objects may be due to this test situation being more complex. If the effect of anxiolytics on exploration is dependent on the complexity of the test situation, this may account for the discrepant reports in the literature on the effects on exploration of CDP $(5 \mathrm{mg} / \mathrm{kg}$ ) (e.g., Hughes \& Grieg, 1975; Marriott \& Smith, 1972). However, an alternative explanation should be considered. It may be that anxiolytics act to increase exploration when this is at a relatively low level, but fail to have such a marked effect at higher levels of exploration. An extreme example of this argument is the "ceiling" effect where the control level is so high as to preclude any significant increase. There was no ceiling effect in this experiment, since the rats had $600 \mathrm{sec}$ available for head-dipping; but, nevertheless, it is possible that the critical factor in determining the effect of anxiolytics is the level of control responses and not the complexity of the test per se.

A similar consideration should be made in interpreting the failure of the CDP-injected rats to show habituation on Trial 2 . The $7.5-\mathrm{mg} / \mathrm{kg}$ group showed an increase in exploration from Trial 1 to Trial 2 . It is possible that the rats in this group had too low a level of exploration on Trial 1 to gain sufficient information for the situation to have become familiar by Trial 2. Kumar (1971) has also reported that $7.5 \mathrm{mg} / \mathrm{kg}$ CDP reduces exploration, measured by trough investigation, on Trial 1 , but that with this dose, exploration increased from Trial 1 to Trial 5.

However, it is unlikely that the failure to habituate is due solely to a reduced level of exploration. First, the $5-\mathrm{mg} / \mathrm{kg}$ group also failed to show significant habituation when tested in the presence of objects, even though this dose produced no change in the frequency or duration of head-dipping. Second, the within-session analysis of habituation (see Figure 3) also suggested an impairment in habituation with CDP, again in a situation where there was no drug-induced change in the level of response.

Similar results were reported by Rushton and Steinberg (1966), who found that CDP produced an initial increase in motor activity, followed by im- mobility, but that the same level of activity recurred when the rats were replaced for a second trial. The impairment in habituation was seen only with CDP and not with ethanol and is therefore unlikely to be related to an anxiolytic effect.

Low doses of both drugs increased exploration on Trial 1, which is consistent with an anxiolytic effect. However, such effects were dependent on the nature of the test situation, either directly on its complexity or indirectly via changes in the level of responding. In addition to this effect, which they had in common, each drug produced a specific impairment. Ethanol reduced the response to a stimulus change in the test situation, and CDP impaired habituation of exploration.

\section{REFERENCES}

AItKen, P. P. Early experience, emotionality and exploration in the rat: A critique of Whimbey and Denenberg's hypothesis. Developmental Psychobiology, 1974, 7, 278-282.

ARCHER, J. Tests for emotionality in rats and mice: A review. Animal Behaviour, 1973, 21, 205-235.

DENENBERG, V. H. Open-field behaviour in the rat: What does it mean? Annals of New York Academy of Sciences, 1969, 159, 852-859.

FILE, S. E., \& DAY, S. Effects of time of day and food deprivation on exploratory activity in the rat. Animal Behaviour, 1972, 20, 758-762.

FILE, S. E., \& W ARdill, A. G. The reliability of the hole-board apparatus. Psychopharmacologia, 1975, 44, 47-51. (a)

File, S. E., \& Wardill, A. G. Validity of head-dipping as a measure of exploration in a modified hole-board. Psychopharmacologia, 1975, 44, 53-59. (b)

Halliday, M. S. Exploratory behaviour in elevated mazes. Quarterly Journal of Experimental Psychology, 1967, 19. 254-263.

HAlliday, M. S. Exploratory behaviour. In L. Weiskrantz (Ed.), Analysis of behavioral change. New York: Harper \& Row, 1968. Pp. 107-126.

Hughes, R. N. Chlordiazepoxide modified exploration in rats. Psychopharmacologia, 1972, 24, 462-469.

Hughes, R. N., \& Grieg, A. M. Chlordiazepoxide effects on reactions to novelty and activity with and without prior drug experience. Psychopharmacologia, 1975, 42, 289-292.

King, D. L., \& Appelbaum, J. R. Effect of trials on "emotionality" behaviour of the rat and mouse. Journal of Comparative and Physiological Psychology, 1973, 85, 186-191.

KUMAR, R. Extinction of fear II: Effects of chlordiazepoxide and chlorpromazine on fear and exploratory behaviour in rats. Psychopharmacologia, 1971, 19, 297-312.

Marriott, A. S., \& SMith, E. F. An analysis of drug effects in mice exposed to a simple novel environment. Psychopharmacologia, (Berl.) 1972, 24, 397-406.

Nolan, N. A., \& Parkes, M. W. The effects of benzodiazepines on the behaviour of mice on the holeboard. Psychopharmacologia, (Berl.) 1973, 29, 277-288.

Rushton, R., \& Steinberg, H. Combined effects of chlordiazepoxide and dexamphetamine on activity of rats in an unfamiliar environment. Nature, 1966, 211, 1312-1313.

Russell, P. A. Sex differences in stationary-cage activity measured by observation and automatic recording. Animal Learning \& Behavior, 1973, 1, 278-282.

(Received for publication August 19, 1976; revision accepted October $8,1976$. 